\title{
Characterization of Pseudomonas aeruginosa isolates from patients with endophthalmitis using conventional microbiologic techniques and whole genome sequencing
}

Jesse D. Sengillo, Jacob Duker, Maribel Hernandez, Jorge Maestre, Daniela Reyes-Capo, Annika Patel, Arjun Watane, Nimesh A. Patel, Nicolas A. Yannuzzi, Darlene Miller and Harry W. Flynn Jr (iD

\begin{abstract}
Purpose: To demonstrate antibiotic susceptibility and genomic virulence factor profiles of Pseudomonas aeruginosa isolates from patients with culture-confirmed endophthalmitis.

Methods: Clinical isolates from patients diagnosed with pseudomonas endophthalmitis were included. Laboratory antibiotic susceptibility testing and whole genome sequencing was performed on all isolates.

Results: In the current study, 8 patients had vitreous culture-confirmed endophthalmitis due to P. aeruginosa. All isolates were multi-drug resistant but sensitive to ceftazidime and each fluoroquinolone tested. Whole genome sequencing revealed a total of 179 unique genes. The most common type of virulence genes included those involved in adherence and the secretion system. Seven of 8 (88\%) isolates were of the cytoinvasive phenotype (exoST) and no isolates contained exoU.

Conclusions: P. aeruginosa associated endophthalmitis is often multi-drug resistant and demonstrates a variety of virulence factors with those involved in adherence and the secretion system being the most common.
\end{abstract}

Keywords: Pseudomonas aeruginosa, Whole genome sequencing, Endophthalmitis

\section{Background}

Infectious endophthalmitis is a severe sight-threatening entity that can occur post-operatively, following trauma, or coincident with systemic infection. In the Endophthalmitis Vitrectomy Study (EVS) study, 36\% of patients with endophthalmitis failed to achieve better than $20 / 100$ visual acuity at 9 to 12 months [1]. Though just $4.1 \%$ of isolates in the EVS study were gram-negative organisms, other studies suggest a higher incidence that ranges from 10 to $24 \%$ [2-8]. Among gram-negative endophthalmitis cases,

\footnotetext{
* Correspondence: HFlynn@med.miami.edu

Department of Ophthalmology, Bascom Palmer Eye Institute, University of Miami Miller School of Medicine, 900 NW 17th Street, Miami, FL 33136, USA
}

Pseudomonas aeruginosa is the most commonly isolated organism [3, 9-12] and is associated with a more fulminant clinical course and higher evisceration/enucleation rate compared to its gram-positive counterparts [13-15]. In fact, a recent prospective study by Stevenson et al. reported $30 \%$ of patients with gram negative endophthalmitis requiring evisceration or enucleation [8].

In addition to the growing prevalence of multi-drug resistant strains, the virulent nature of pseudomonas is often ascribed to factors expressed by its bacterial DNA [16]. These virulence factors contribute to its ability to induce rapid ocular tissue necrosis [6]. Comparative studies correlating these genotypes with clinical features
Springer Open (c) The Author(s). 2020 Open Access This article is licensed under a Creative Commons Attribution 4.0 International License, which permits use, sharing, adaptation, distribution and reproduction in any medium or format, as long as you give appropriate credit to the original author(s) and the source, provide a link to the Creative Commons licence, and indicate if changes were made. The images or other third party material in this article are included in the article's Creative Commons licence, unless indicated otherwise in a credit line to the material. If material is not included in the article's Creative Commons licence and your intended use is not permitted by statutory regulation or exceeds the permitted use, you will need to obtain permission directly from the copyright holder. To view a copy of this licence, visit http://creativecommons.org/licenses/by/4.0/. 
observed in host tissue increase our understanding of pseudomonas pathogenicity [17]. However, there is a paucity of studies which have sought to identify virulence factors implicated in cohorts of pseudomonas keratitis and endophthalmitis $[17,18]$. In the current study, whole genome sequencing (WGS) was performed on isolates to identify associated virulence factors in culture-confirmed pseudomonas endophthalmitis.

\section{Methods}

The current study was approved by the Institutional Review Board of the University of Miami School of Medicine Medical Sciences Subcommittee for the Protection of Human Subjects, and was performed in accordance with the ethical standards as laid down in the 1964 Declaration of Helsinki and later amendments. Clinical and microbiology records were retrospectively reviewed for patients who were evaluated at Bascom Palmer Eye Institute and diagnosed with vitreous culture-confirmed endophthalmitis due to P. aeruginosa. Antibiotic susceptibility profiles were identified using standard microbiologic protocols via an automated system, including the VITEK (Automatic Microbial System; Biomerieux Vitek, Hazelwood, Missouri, USA) which provided 'breakpoint' MICs (minimal inhibitory concentration values) based on the micro dilution method, the E test (A.B. Biodisk, NA; Remel, Lenexa, Kansas, USA), or disk diffusion (antibiotic-impregnated paper disks; Becton Dickinson, Cockeysville, MD). Whole genome sequencing was performed by COSMOS ID (Rockville, MD) using Illumina and Ion Torrent platforms.

\section{Results}

The current study includes 8 patients diagnosed with vitreous culture-confirmed $P$. aeruginosa endophthalmitis at Bascom Palmer Eye Institute. Clinical data is presented in Table 1 . The average age was 74 years (range: 53-84). Four of 8 patients (50\%) were men. Endophthalmitis was diagnosed based on clinical findings and confirmed with vitreous cultures obtained via tap or pars plana vitrectomy. Three of 8 cases (38\%) were in the setting of recent ocular surgery, which included postphacoemulsification $(n=2)$ and post-corneal transplant $(n=1)$. Three cases occurred in the setting of corneal ulceration, with one patient exhibiting scleral extension of infection (P1). One case followed an open globe injury with a retained intraocular foreign body. Multiple organisms grew from vitreous cultures in two patients, namely Staphylococcus aureus (P5) and Staphylococcus hominis (P7).

Average follow-up time for patients in this cohort was 2 years. Clinical presentation, treatment strategy, and visual outcomes are detailed in Table 2. Baseline visual acuity prior to diagnosis of endophthalmitis was not available. Vision at presentation was hand motions or light perception for all patients with documented visual acuity (7 of 8 patients). Final visual outcome ranged from $20 / 400$ to no light perception, with 2 patients ultimately requiring enucleation. Intravitreal tap and injection of antibiotics were used as initial treatment for 5 of 8 cases, while pars plana vitrectomy (PPV) with intraoperative intravitreal injections was performed initially in 2 of 8 cases. For P1 and P4, data was not available regarding initial type of intravitreal antibiotic and for P3, initial treatment choice (PPV vs intravitreal injections) was not indicated in the medical record.

$P$. aeruginosa was identified from the vitreous sample of each patient. Antibiotic sensitivities are summarized in Table 3 and minimum inhibitory concentration values are reported in Supplemental Table 1. All isolates were multi-drug resistant with similar resistance profiles. Sensitivity to ceftazidime was identified across the entire cohort. Vancomycin resistance was not specifically tested, but all isolates were sensitive to the fourth generation cephalosporin, cefepime. Sensitivity to all tested aminoglycosides and fluoroquinolones was seen in all isolates in this cohort, including the newest fluoroquinolone, delafloxacin. Resistance to first- and second- generation cephalosporins, cefazolin and cefoxitin respectively, ampicillin, ampicillin/sulbactam, ceftriaxone, and

Table 1 Clinical characteristics of of patients with endophthalmitis due to Pseudomonas aeruginosa

\begin{tabular}{|c|c|c|c|c|c|c|}
\hline Patient & Sex & Age (yrs) & Clinical setting & Concurrent corneal ulcer & Time after surgery & Additional isolates from vitreous \\
\hline 1 & $\mathrm{~F}$ & 81 & Sclerokeratitis & Yes & - & - \\
\hline 2 & $\mathrm{~F}$ & 69 & Post phacoemulsification & No & 5 days & - \\
\hline 3 & $\mathrm{~F}$ & 80 & UK & UK & UK & - \\
\hline 4 & M & 71 & Corneal ulcer & Yes & - & - \\
\hline 5 & M & 84 & Postoperative phacoemulsification & No & 5 days & Staphylococcus aureous \\
\hline 6 & $\mathrm{~F}$ & 80 & Post corneal transplant & No & 8 days & - \\
\hline 7 & M & 78 & Corneal ulcer & Yes & - & Staphylococcus hominis \\
\hline 8 & M & 53 & Globe rupture with IOFB & No & - & - \\
\hline
\end{tabular}

Clinical characteristics of patients with $P$. aeruginosa isolated from vitreous cultures in this cohort

Abbreviations: UK unknown, - not applicable, IOFB intraocular foreign body. Detailed clinical records were not available for P3 
Table 2 Presentation, treatment strategies, and outcomes of patients with endophthalmitis caused by Pseudomonas aeruginosa

\begin{tabular}{|c|c|c|c|c|c|c|c|c|}
\hline No. & $\begin{array}{l}\text { Baseline } \\
\text { VA }\end{array}$ & $\begin{array}{l}\text { Initial } \\
\text { VA }\end{array}$ & Initial Tx & Initial IVTI & $\begin{array}{l}\text { Additional Tx } \\
\text { (Days after presentation) }\end{array}$ & $\begin{array}{l}\text { Additional IVTI } \\
\text { (Days after } \\
\text { presentation) }\end{array}$ & Last VA & $\begin{array}{l}\text { Follow-up } \\
\text { time }\end{array}$ \\
\hline 1 & UK & $L P$ & $T+1$ & Unknown & PPV (1) & $\begin{array}{l}\mathrm{Cfx}(2) \\
\mathrm{Ctz}(3)\end{array}$ & NLP & 2 years \\
\hline 2 & UK & $L P$ & PPV & $\begin{array}{l}\text { Vanc }+C t z \\
\text { (intra-op) }\end{array}$ & Enucleation & - & Enucleation & 7 years \\
\hline 3 & UK & UK & UK & UK & UK & UK & UK & UK \\
\hline 4 & UK & $\mathrm{HM}$ & $T+1$ & UK & Enucleation (6) & - & Enucleation & 8 months \\
\hline 5 & UK & $L P$ & $T+1$ & Vanc $+C t z+D e x$ & PPV (4) & $\begin{array}{l}\text { Vanc + Dex (4) } \\
\text { Ctz (8) }\end{array}$ & CF & 3 months \\
\hline 6 & UK & $L P$ & $T+1$ & $\operatorname{Vanc}+C t z$ & PPV (4) & $\begin{array}{l}\text { Ctz }(2 \& 8) \\
\text { Ctz intra-op (4) }\end{array}$ & LP & 2 days \\
\hline 7 & UK & $L P$ & $T+1$ & $\mathrm{Ctz}+$ Vanc & - & $\begin{array}{l}\text { Vanc + Dex (2) } \\
\text { Vanc + Ctz + Dex (5) }\end{array}$ & LP & 4 years \\
\hline 8 & UK & $\mathrm{HM}$ & $\begin{array}{l}\text { Globe } \\
\text { repair } \\
\text { PPV }\end{array}$ & $\begin{array}{l}\text { Vanc + Ctz + Vcz (intra- } \\
\text { op) }\end{array}$ & $\begin{array}{l}\text { Retinal detachment repair ( } 4 \\
\text { months) }\end{array}$ & - & $20 / 400$ & 2 years \\
\hline
\end{tabular}

Presentation, treatment strategies, and outcomes of patients with endophthalmitis caused by Pseudomonas aeruginosa in this cohort

Abbreviations: VA visual acuity, NLP no light perception, $L P$ light perception, HM hand motions, UK unknown, $T x$ treatment, $I V T I$ intravitreal injection, $T+I$ vitreous tap and intravitreal injection, PPV pars plana vitrectomy, Vanc vancomycin, Ctz ceftazidime, Cfx cefuroxime, Dex dexamethasone, Vcz voriconazole, not applicable

Table 3 Antibiotic sensitivities of Pseudomonas aeruginosa vitreous isolates

\begin{tabular}{|c|c|c|c|c|c|c|c|c|}
\hline \multirow[b]{2}{*}{ Antibiotic } & \multicolumn{8}{|c|}{ Vitreous isolate sensitivities } \\
\hline & 1 & 2 & 3 & 4 & 5 & 6 & 7 & 8 \\
\hline Ampicillin & R & $\mathrm{R}$ & $\mathrm{R}$ & $\mathrm{R}$ & R & $\mathrm{R}$ & R & $\mathrm{R}$ \\
\hline Amp/Sulbactam & R & $\mathrm{R}$ & $\mathrm{R}$ & $\mathrm{R}$ & $\mathrm{R}$ & R & $\mathrm{R}$ & $\mathrm{R}$ \\
\hline Piper/Tazo & s & - & S & s & S & S & S & $S$ \\
\hline Ticar/Clav & - & S & - & - & - & - & - & - \\
\hline Cefazolin & R & $\mathrm{R}$ & $\mathrm{R}$ & R & $\mathrm{R}$ & R & $\mathrm{R}$ & $\mathrm{R}$ \\
\hline Cefoxitin & R & R & $\mathrm{R}$ & R & $\mathrm{R}$ & R & $\mathrm{R}$ & $\mathrm{R}$ \\
\hline Ceftazidime & s & S & S & s & S & S & S & S \\
\hline Ceftriaxone & R & R & R & R & R & R & R & $\mathrm{R}$ \\
\hline Cefepime & S & S & S & S & S & S & S & S \\
\hline Imipenem & S & S & S & S & S & S & S & $\mathrm{S}$ \\
\hline Meropenem & S & - & S & S & S & S & S & S \\
\hline Levofloxacin & S & S & S & S & S & S & $S$ & $S$ \\
\hline Ciprofloxacin & S & S & S & S & S & S & S & S \\
\hline Moxifloxacin & S & S & S & S & S & S & S & $\mathrm{S}$ \\
\hline Delafloxacin & S & S & S & S & S & S & S & $\mathrm{S}$ \\
\hline Gentamicin & S & S & S & S & S & S & S & S \\
\hline Amikacin & S & S & $\mathrm{s}$ & S & S & S & S & S \\
\hline Tobramycin & S & S & S & S & S & S & S & $\mathrm{S}$ \\
\hline Trimeth/Sulfa & R & $\mathrm{R}$ & R & R & R & R & S & R \\
\hline Nitrofurantoin & $\mathrm{R}$ & $\mathrm{R}$ & $\mathrm{R}$ & $\mathrm{R}$ & $\mathrm{R}$ & $\mathrm{R}$ & $\mathrm{R}$ & $\mathrm{R}$ \\
\hline
\end{tabular}

Antibiotic sensitivities of Pseudomonas aeruginosa vitreous isolates from patients with endophthalmitis. Sensitivities were calculated with the VITEK-2 automated system, E-test, or disk diffusion testing. S, sensitive; R, resistant; - , not tested

Abbreviations: Amp/Sulbactam Ampicillin/Sulbactam, Piper/Tazo Piperacillin/Tazobactam, Ticar/Clav Ticarcillin/Clavulanic acid, Trimeth/Sulfa Trimethoprim/Sulfamethoxazole nitrofurantoin across all isolates was observed. Seven of $8(88 \%)$ isolates were resistant to sulfamethoxazole/ trimethoprim.

All isolates in this study underwent WGS to identify known virulence factors. A total of 1087 virulence genes (179 unique) were identified, with an average of 136 genes per isolate. The number of genes for a particular virulence class in the cohort and per isolate is summarized in Table 4. Genes involved in adherence were among the most prevalent (69 unique genes), followed by those involved in secretion systems $(n=47)$, antiphagocytosis $(n=21)$, and iron uptake $(n=13)$. Regarding genes implicated in the type III secretion system (T3SS), all isolates harbored exoT and 7 of 8 isolates (88\%) were found to have exoS, while no isolates contained exou. Isolates were identical with regards to virulence genes known to be involved in protease functions, regulation, biosurfactant, and pigmentation. Among the remaining virulence classes there was a high level of homogeneity with only $22 \%$ of genes being represented in less than half of the isolates. All virulence genes identified in this study are listed in Supplemental Table 2.

\section{Discussion}

The World Health Organization declared $P$. aeruginosa as a critical priority amongst current pathogens urgently in need of new effective antibiotics [19, 20]. A recent study in South India showed a rising resistance to fluoroquinolones, amikacin, and ceftazidime in pseudomonas endophthalmitis, particularly in post-surgical cases [21]. Comparable retrospective studies performed in the United States have not observed a similar increase in resistance yet [14]. In the present study, cultures were 
Table 4 Virulence gene classes identified in cohort

\begin{tabular}{|c|c|c|c|c|}
\hline \multirow[b]{2}{*}{ Virulence class } & \multicolumn{2}{|l|}{ Total genes } & \multirow{2}{*}{$\begin{array}{l}\text { Unique Genes } \\
\text { No. in cohort }\end{array}$} & \multirow[b]{2}{*}{ Class represented in all isolates (yes/no) } \\
\hline & No. in cohort & Average per isolate & & \\
\hline Adherence & 410 & 51.3 & 69 & Yes \\
\hline Secretion System & 258 & 32.3 & 47 & Yes \\
\hline Anti-phagocytosis & 152 & 19.0 & 21 & Yes \\
\hline Iron uptake & 61 & 7.6 & 13 & Yes \\
\hline Motility & 53 & 6.6 & 8 & Yes \\
\hline Toxin & 38 & 4.8 & 5 & Yes \\
\hline Regulation & 32 & 4.0 & 4 & Yes \\
\hline Protease & 24 & 3.0 & 3 & Yes \\
\hline Biosurfactant & 16 & 2.0 & 2 & Yes \\
\hline Pigment & 16 & 2.0 & 2 & Yes \\
\hline Exoenzyme & 8 & 1 & 1 & Yes \\
\hline Endotoxin & 2 & 1 & 1 & No (2/8 isolates) \\
\hline Other & 17 & 2.1 & 3 & Yes \\
\hline Total & 1087 & 136 & 179 & \\
\hline
\end{tabular}

Genes identified among Pseudomonas aeruginosa isolates from vitreous cultures of patients with endophthalmitis using whole genome sequencing

performed between 2011 and 2018, with the majority of patients (5 of 8) presenting in 2015 or later. All isolates were sensitive to ceftazidime, which is generally used as a first line intravitreal antibiotic along with vancomycin at this institution. Interestingly, isolates were pansensitive to fluoroquinolones tested, including delafloxacin, a newly registered fluoroquinolone not currently used in the treatment of ocular infections [22]. This resistance profile suggests there may be significant geographic variation, which may be better studied in larger cohorts. Specialists should consider local resistance patterns when determining treatment.

$P$. aeruginosa expresses many virulence factors that contribute to its pathogenicity in ocular tissue [18]. In the current study, the most represented virulence factors were those involved in adherence with a total of 69 unique genes of this class identified. Proteins expressed by these genes likely allow pseudomonas to adhere to various intraocular structures. Unique to post operative endophthalmitis, intraocular foreign material, such as a lens implant can serve as a surface for bacteria to attach, and potentially as a nidus for bacteria to grow within a biofilm. Some of the most cited genes implicated in biofilm production include $\operatorname{alg} D$, rhlR, rpoS, and $r p o N$, the latter two providing anti-phagocytotic capability against host defenses [23-25]. All isolates contained these genes with the exception of rpoN. Notably not identified by whole genome sequencing in this cohort were $p s l D$, pelF, and gacS, genes previously determined to be common amongst biofilm-producing pseudomonas isolates [23, $25]$. Genes involved in c-di-GMP regulation are also well-established in the pathophysiology of biofilm production, but were not surveyed in this study, including siaD, nbdA, dipA, cdrA, PA4781, or PA4108 [26]. However, identifying these genes and performing functional assays of clinical isolates in future studies could provide a new avenue for understanding biofilm potential and prevalence in endophthalmitis isolates.

In the current study, all isolates harbored the gene encoding exoenzyme $\mathrm{T}$ (exoT). All but one isolate harbored both exoS and exoY, while exoU was not identified. These genes express toxins involved in the T3SS. T3SS is a complex of cellular structures and proteins that allows gram negative organisms to inject proteins directly into host cells, thereby circumventing extracellular obstacles [27]. Exoenzymes are the effector proteins of this system [18]. Generally, strains possessing exoS and exoT are invasive while strains possessing exoU are observed to be cytotoxic in nature. Consistent with previous studies, exoS and exoU were mutually exclusive, as all strains that contained exoS, did not have exoU [28-30]. Interestingly, previous reports suggest a predominance of exo $U$ strains in isolates from keratitis [28], though even in endophthalmitis arising in the setting of a corneal ulcer in this cohort, this cytotoxic genotype was not present. This may suggest that pseudomonas with a predilection for endophthalmitis may be more commonly of the cytoinvasive type (exoST). Lastly, the exoU genotype is associated with fluoroquinolone resistance in previously studied clinical isolates [31, 32]. The putative correlation of pan-sensitivity to fluoroquinolones and lack of exoU genotype in this cohort should be confirmed in larger studies.

To the authors' knowledge, this is the first report in which WGS was used to characterize pseudomonas 
isolates from vitreous cultures of patients with endophthalmitis. As gene expression assays and functional tests were not performed, the authors cannot guarantee that the presence of a virulence gene indicates a role for the respective factor in pseudomonas pathogenesis. Additionally, variability in the clinical context of infection and relative genetic homogeneity between isolates limits the clinical correlations that can be made. Specifically, in this cohort endophthalmitis occurred in the setting of ocular surface disease for 3 patients, post-surgically for 3 patients, and in the setting of trauma for one patient. It is likely that the setting in which infection occurs and the interplay of pseudomonas with host factors play a large role in disease pathogenesis as well [33]. Elucidating this interaction will require a larger cohort. Lastly, in the present study, the genotypic spectrum identified from pseudomonas endophthalmitis isolates were not compared to environmental strains. Such comparisons in future studies would help confirm if particular virulence factors are more common in the setting of endophthalmitis.

\section{Conclusions}

In the current study of $P$. aeruginosa isolates from patients with endophthalmitis, infection occurred in a variety of clinical settings and all organisms were multidrug resistant. Using whole genome sequencing, many unique virulence factors were identified, with those involved in bacterial adherence, the secretion system, and anti-phagocytosis being the most common. This investigation increases current understanding of the pathogenesis of $P$. aeruginosa endophthalmitis and emphasizes the need for further investigation of these mechanisms.

\section{Supplementary information}

Supplementary information accompanies this paper at https://doi.org/10. 1186/s12348-020-00216-0.

Additional file 1 : Table S1. Antibiotic sensitivity values for individual isolates.

Additional file $\mathbf{2}$ : Table S2. Virulence factor genes identified in cohort.

\section{Abbreviations}

P. aeruginosa: Pseudomonas aeruginosa; EVS: Endophthalmitis Vitrectomy Study; WGS: Whole genome sequencing; PPV: Pars plana vitrectomy; T3SS: Type III secretion system

\section{Acknowledgements}

None

\section{Disclosures}

The authors have no relevant financial disclosures.

\section{Authors' contributions}

JDS and HF wrote the manuscript. MH and JM provided technical assistance with laboratory studies. JD, DRC, AP, AW, NAP, and NAY assisted in data collection and manuscript editing. DM and HF designed the study and interpreted the final results. All authors read and approved the final manuscript.

\section{Funding}

This study was supported in part by an unrestricted grant from Research to Prevent Blindness (New York, New York), NIH Center Core Grant P30EY014801 (Bethesda, Maryland), and the Department of Defense (DOG Grant \#W81XWH-09-1-0675) (Washington, D.C.). The sponsor or funding organization had no role in the design or conduct of this study.

\section{Availability of data and materials}

The datasets generated and/or analyzed during the current study are available from the corresponding author on reasonable request.

Ethics approval and consent to participate

The current study was approved by the Institutional Review Board of the University of Miami School of Medicine Medical Sciences Subcommittee for the Protection of Human Subjects.

\section{Consent for publication}

Not applicable.

\section{Competing interests}

The authors declare that they have no competing interests.

Received: 6 July 2020 Accepted: 4 September 2020

Published online: 28 September 2020

References

1. Results of the Endophthalmitis Vitrectomy Study (1995) A randomized trial of immediate vitrectomy and of intravenous antibiotics for the treatment of postoperative bacterial endophthalmitis. Endophthalmitis Vitrectomy Study Group. Arch Ophthalmol 113:1479-1496

2. Fan JC, Niederer RL, von Lany H, Polkinghorne PJ (2008) Infectious endophthalmitis: clinical features, management and visual outcomes. Clin Exp Ophthalmol 36:631-636. https://doi.org/10.1111/j.1442-9071. 2008.01813.x

3. Schimel AM, Miller D, Flynn HW Jr (2013) Endophthalmitis isolates and antibiotic susceptibilities: a 10-year review of culture-proven cases. Am J Ophthalmol 156:50-52 e51. https://doi.org/10.1016/j.ajo.2013.01.027

4. Gupta A, Orlans HO, Hornby SJ, Bowler IC (2014) Microbiology and visual outcomes of culture-positive bacterial endophthalmitis in Oxford, UK. Graefes Arch Clin Exp Ophthalmol 252:1825-1830. https://doi.org/10.1007/ s00417-014-2658-7

5. Moloney TP, Park J (2014) Microbiological isolates and antibiotic sensitivities in culture-proven endophthalmitis: a 15-year review. Br J Ophthalmol 98: 1492-1497. https://doi.org/10.1136/bjophthalmol-2014-305030

6. Dave VP, Pathengay A, Nishant K et al (2017) Clinical presentations, risk factors and outcomes of ceftazidime-resistant gram-negative endophthalmitis. Clin Exp Ophthalmol 45:254-260. https://doi.org/10.1111/ ceo. 12833

7. Liu C, Ji J, Li S et al (2017) Microbiological isolates and antibiotic susceptibilities: a 10-year review of culture-proven endophthalmitis cases. Curr Eye Res 42:443-447. https://doi.org/10.1080/02713683.2016.1188118

8. Stevenson LJ, Dawkins RCH, Sheorey H, McGuiness MB, Hurley AH, Allen PJ (2020) Gram-negative endophthalmitis: a prospective study examining the microbiology, clinical associations and visual outcomes following infection. Clin Exp Ophthalmol. https://doi.org/10.1111/ceo.13768

9. Pathengay A, Flynn HW Jr, Isom RF, Miller D (2012) Endophthalmitis outbreaks following cataract surgery: causative organisms, etiologies, and visual acuity outcomes. J Cataract Refract Surg 38:1278-1282. https://doi. org/10.1016/j.jcrs.2012.04.021

10. Bhoomibunchoo C, Ratanapakorn T, Sinawat S, Sanguansak T, Moontawee K, Yospaiboon Y (2013) Infectious endophthalmitis: review of 420 cases. Clin Ophthalmol 7:247-252. https://doi.org/10.2147/OPTH.S39934

11. Lalitha P, Sengupta S, Ravindran RD et al (2017) A literature review and update on the incidence and microbiology spectrum of postcataract surgery endophthalmitis over past two decades in India. Indian J Ophthalmol 65:673-677. https://doi.org/10.4103/ijo.IJO_509_17

12. Yospaiboon $Y$, Intarapanich A, Laovirojjanakul W et al (2018) Factors affecting visual outcomes after treatment of infectious endophthalmitis in 
northeastern Thailand. Clin Ophthalmol 12:765-772. https://doi.org/10.2147/ OPTH.S160758

13. Eifrig CW, Scott IU, Flynn HW Jr, Miller D (2003) Endophthalmitis caused by Pseudomonas aeruginosa. Ophthalmology 110:1714-1717. https://doi.org/10. 1016/50161-6420(03)00572-4

14. Sridhar J, Kuriyan AE, Flynn HW Jr, Miller D (2015) Endophthalmitis caused by Pseudomonas aeruginosa: clinical features, antibiotic susceptibilities, and treatment outcomes. Retina 35:1101-1106. https://doi.org/10.1097/IAE 0000000000000469

15. Falavarjani KG, Amirpooya Alemzadeh S, Habibi A, Hadavandkhani A, Askari S, Pourhabibi A (2017) Pseudomonas aeruginosa endophthalmitis: clinical outcomes and antibiotic susceptibilities. Ocul Immunol Inflamm 25:377-381. https://doi.org/10.3109/09273948.2015.1132740

16. Sawa T, Momiyama K, Mihara T, Kainuma A, Kinoshita M, Moriyama K (2020) Molecular epidemiology of clinically high-risk Pseudomonas aeruginosa strains: practical overview. Microbiol Immunol. https://doi.org/10.1111/13480421.12776

17. Oka N, Suzuki T, Ishikawa E et al (2015) Relationship of virulence factors and clinical features in keratitis caused by Pseudomonas aeruginosa. Invest Ophthalmol Vis Sci 56:6892-6898. https://doi.org/10.1167/iovs.15-17556

18. Lakshmi Priya J, Prajna L, Mohankumar V (2015) Genotypic and phenotypic characterization of Pseudomonas aeruginosa isolates from post-cataract endophthalmitis patients. Microb Pathog 78:67-73. https://doi.org/10.1016/j. micpath.2014.11.014

19. Geneva: World Health Organization (2019) 2019 antibacterial agents in clinical development: an analysis of the antibacterial clinical development pipeline. Available in https://apps.who.int/iris/bitstream/handle/10665/33042 0/9789240000193-eng.pdf. Accessed 24 May 2020.

20. Beyer P, Paulin S (2020) Priority pathogens and the antibiotic pipeline: an update. Bull World Health Organ 98:151. https://doi.org/10.2471/BLT.20. 251751

21. Pan U, Jain A, Gubert J, Kumari B, Sindal MD (2020) Antibiotic sensitivity trends of pseudomonas endophthalmitis in a tertiary eye care center in South India: a 12-year retrospective study. Indian J Ophthalmol 68:627-631. https://doi.org/10.4103/ijo.IJO_1145_19

22. Fan KC, Lin J, Yannuzzi NA et al (2020) In vitro susceptibilities of methicillinsusceptible and resistant staphylococci to traditional antibiotics compared to a novel fluoroquinolone. J Ophthalmic Inflamm Infect 10:9. https://doi. org/10.1186/s12348-020-0200-0

23. Anupama R, Sajitha Lulu S, Mukherjee A et al (2018) Cross-regulatory network in Pseudomonas aeruginosa biofilm genes and $\mathrm{TiO}_{2}$ anatase induced molecular perturbations in key proteins unraveled by a systems biology approach. Gene 647:289-296

24. Mukherjee S, Moustafa DA, Stergioula V et al (2018) The PqsE and RhIR proteins are an autoinducer synthase-receptor pair that control virulence and biofilm development in Pseudomonas aeruginosa. Proc Natl Acad Sci U S A 115:E9411-E9418

25. Kamali E, Jamali A, Ardebili A, Ezadi F, Mohebbi A (2020) Evaluation of antimicrobial resistance, biofilm forming potential, and the presence of biofilm-related genes among clinical isolates of Pseudomonas aeruginosa. BMC Res Notes 13:27

26. Valentini M, Filloux A (2016) Biofilms and cyclic di-GMP (c-di-GMP) signaling: lessons from pseudomonas aeruginosa and other bacteria. J Biol Chem 291: 12547-12555. https://doi.org/10.1074/jbc.R115.711507

27. Coburn B, Sekirov I, Finlay BB (2007) Type III secretion systems and disease. Clin Microbiol Rev 20:535-549. https://doi.org/10.1128/CMR.00013-07

28. Stewart RM, Wiehlmann L, Ashelford KE et al (2011) Genetic characterization indicates that a specific subpopulation of Pseudomonas aeruginosa is associated with keratitis infections. J Clin Microbiol 49:993-1003. https://doi. org/10.1128/JCM.02036-10

29. Yamaguchi S, Suzuki T, Kobayashi T et al (2014) Genotypic analysis of Pseudomonas aeruginosa isolated from ocular infection. J Infect Chemother 20:407-411. https://doi.org/10.1016/j.jiac.2014.02.007

30. Subedi D, Vijay AK, Kohli GS, Rice SA, Willcox M (2018) Comparative genomics of clinical strains of Pseudomonas aeruginosa strains isolated from different geographic sites. Sci Rep 8:15668. https://doi.org/10.1038/s41598018-34020-7

31. Wong-Beringer A, Wiener-Kronish J, Lynch S, Flanagan J (2008) Comparison of type III secretion system virulence among fluoroquinolone-susceptible and -resistant clinical isolates of Pseudomonas aeruginosa. Clin Microbiol Infect 14:330-336. https://doi.org/10.1111/j.1469-0691.2007.01939.x
32. Agnello M, Wong-Beringer A (2012) Differentiation in quinolone resistance by virulence genotype in Pseudomonas aeruginosa. PLoS One 7:e42973. https://doi.org/10.1371/journal.pone.0042973

33. Crousilles A, Maunders E, Bartlett S et al (2015) Which microbial factors really are important in Pseudomonas aeruginosa infections? Future Microbiol 10:1825-1836

\section{Publisher's Note}

Springer Nature remains neutral with regard to jurisdictional claims in published maps and institutional affiliations.

\section{Submit your manuscript to a SpringerOpen ${ }^{\circ}$ journal and benefit from:}

- Convenient online submission

- Rigorous peer review

- Open access: articles freely available online

- High visibility within the field

- Retaining the copyright to your article

Submit your next manuscript at $\boldsymbol{\nabla}$ springeropen.com 